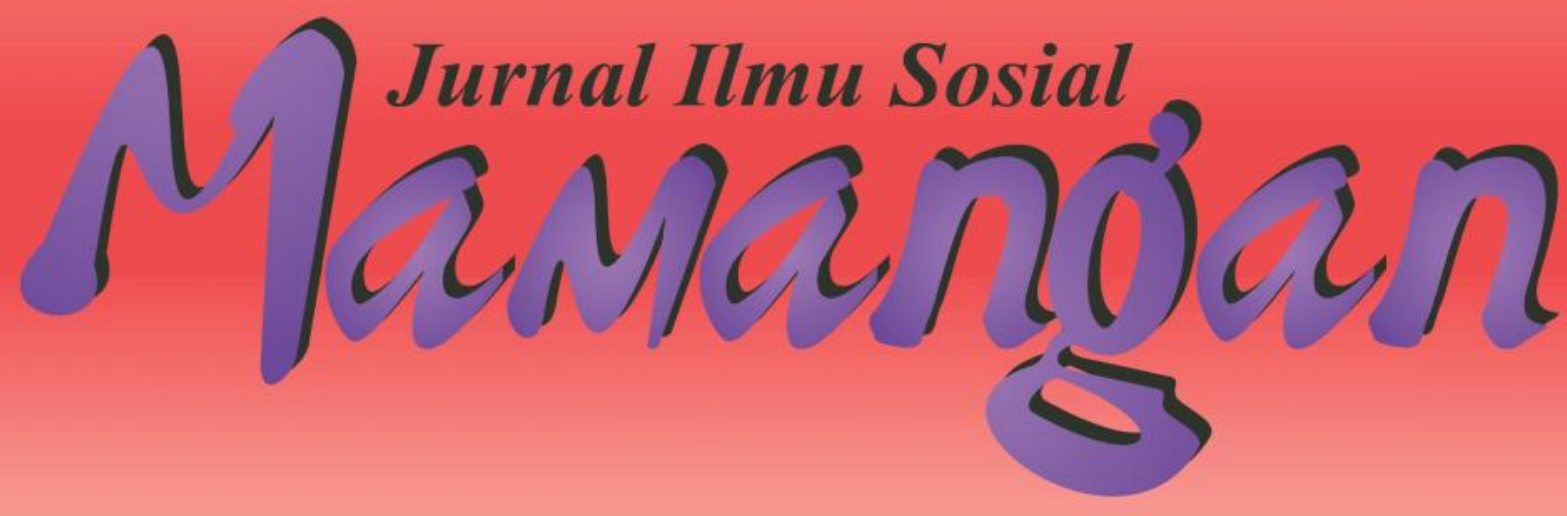

Peran Perantau Terhadap Pembangunan Di Jorong Galogandang, Nagari III Koto Kec. Rambatan, Kab. Tanah Datar Vivi Emita, Zusmelia \& Marleni

Julo-Julo Tani Buruh Perempuan Jorong Patamuan, Nagari Talu Kecamatan Talamu Kab. Pasaman Barat Sriwahyuni, Zusmelia \& Delmira Syafirini

Dari Petani Ke Penambang; Perubahan Sosial Ekonomi Di Jorong Koto Panjang, Nagari Limo Koto, Kabupaten Sijunjung

Melta Ardila Sari, Ardi Abbas \& Darmairal Rahmad

Strategi Masyarakat Multikultural Pasaman Barat Menghindari Konflik

Elly Kristin Debora, Dian Kurnia Anggreta \& Faishal Yasin

Konflik Sopir PO. Mitra Kencana Vs Pengemudi Betor di Air Bangis, Kab. Pasaman Barat

Helma Frida, Witrianto \& ZusneliZubir

Konflik Tanah Ulayat Antara Kamanakan Malakok VS Niniak Mamak Suku Tobo Di Nagari Padang Laweh, Kec. Koto VII, Kab. Sijunjung Welda Ningsih, Dian Kurnia Anggreta \& Rinel Fitlayeni 


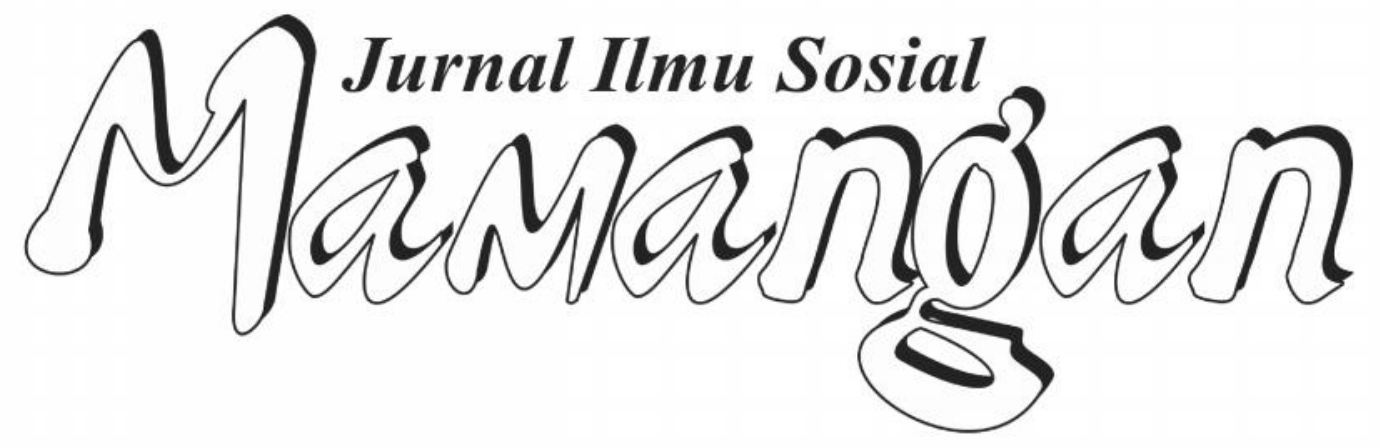




\section{Mitra Bestari}

Prof. Dr. Afrizal, MA. (FISIP, Unand Padang)

Dr. A. Latief Wiyata, M. Si. (Universitas Jember, Jember)

Prof. Dr. Badaruddin, M. Si. (FISIP, USU Medan)

Dr. Fikarwin Zuska, M. Si. (FISIP, USU Medan)

Nurus Shalihin, M. Si., Ph.D. (Fak. Ushuluddin IAIN Imam Bonjol Padang)

Dr. Semiarto A. Purwanto, M. Si. (FISIP, UI Jakarta)

Dr. Wahyu Wibowo, M. Si. (Universitas Nasional, Jakarta)

\section{Dewan Redaksi}

Dr. Zusmelia, M. Si.

Dr. Maihasni, M. Si.

Adiyalmon, S. Ag., M. Pd.

Firdaus, S. Sos., M. Si.

\section{Pemimpin Redaksi}

Firdaus, S. Sos., M. Si.

\section{Anggota Redaksi}

Dian Kurnia Anggreta, S. Sos., M. Si.

Rinel Fitlayeni, S. Sos., MA.

Surya Prahara, SH.

ISSN: 2301-8496

\section{Alamat Redaksi:}

Laboratorium Program Studi Pendidikan Sosiologi, STKIP PGRI Padang

Jl. Gunung Pangilun, Padang

Email: redaksimamangan@yahoo.com

Penerbit :

Program Studi Pendidikan Sosiologi, STKIP PGRI Padang

\section{Contac person :}

Firdaus (Hp. 085263881221/Email : daus gila@yahoo.com) 


\section{DAFTAR ISI}

Peran Perantau Terhadap Pembangunan Di Jorong Galogandang, Nagari III Koto Kec. Rambatan, Kab. Tanah Datar

Vivi Emita, Zusmelia \& Marleni

Julo-Julo Tani Buruh Perempuan Jorong Patamuan, Nagari Talu Kecamatan Talamu Kab. Pasaman Barat

Sriwahyuni, Zusmelia \& Delmira Syafirini

Dari Petani Ke Penambang; Perubahan Sosial Ekonomi Di Jorong Koto Panjang, Nagari Limo Koto, Kabupaten Sijunjung

Melta Ardila Sari, Ardi Abbas \& Darmairal Rahmad

Strategi Masyarakat Multikultural Pasaman Barat Menghindari Konflik

Elly Kristin Debora, Dian Kurnia Anggreta \& Faishal Yasin

Konflik Sopir P0. Mitra Kencana Vs Pengemudi Betor di Air Bangis, Kab. Pasaman Barat

Helma Frida, Witrianto \& Zusneli Zubir

Konflik Tanah Ulayat Antara Kamanakan Malakok VS Niniak Mamak Suku Tobo Di Nagari Padang Laweh, Kec. Koto VII, Kab. Sijunjung Welda Ningsih, Dian Kurnia Anggreta \& Rinel Fitlayeni. 


\title{
DARI PETANI KE PENAMBANG; Perubahan Sosial Ekonomi Di Jorong Koto Panjang, Nagari Limo Koto, Kabupaten Sijunjung
}

\author{
Melta Ardila Sari ${ }^{1}$, Ardi Abbas $^{2}$ \& Darmairal Rahmad ${ }^{3}$ \\ 1,3Sekolah Tinggi Keguruan dan Ilmu Pendidikan (STKIP) PGRI Sumatera Barat \\ 2 Universitas Andalas
}

\begin{abstract}
This paper discusses the socio-economic changes are turning farmers livelihoods to miners in Jorong Koto Panjang. This reasearch background of the rice made in gold mines so that a shift of livelihoods, and cousing consumer behavior. The mining activities are at risk of exhaustion of the gold content, on the one hand the life of the community is still running. This condition has implications for the socioeconomic status of the family owners of the fields after the gold miner. Therefore, in this paper seeks to unravel the activities of miners, and to describe the socio-economic conditions of the post-mining of gold miners. This study uses qualitative research and descriptive. Informal election in this study using purposive sampling technique. This type of data is primary data and secondary data. Data collection is observation, interviews. The results of the post-mining research of gold in no tackling, which has exhausted tilled rice fields be left just like that becomes a swamp and sand. Post-mining social status housewife, taxi of motorcydrivers, farm workers and laborers gold miner. Also a decline in revenue.
\end{abstract}

\section{Keyword :Socio-economic, Miners, Livelihood Changes}

\begin{abstract}
ABSTRAK
Tulisan ini membahas perubahan sosial ekonomi para petani yang beralih mata pencarian menjadi penambang di Jorong Koto Panjang Kecamatan. Penelitian ini di latarbelakangi oleh sawah yang di jadikan tambang emas sehinga terjadi peralihan mata pencarian masyarakat, serta menimbulkan perilaku konsumtif. Aktifitas penambangan ini beresiko, seperti habisnya kandungan emas, disatu sisi kehidupan masyarakat tetap berjalan. Kondisi ini berimplikasi kepada status sosial ekonomi keluarga pemilik sawah pasca penambang emas. Oleh karena itu, dalam tulisan ini berupaya mengurai aktifitas penambang emas, serta mendeskripsikan kondisi sosial ekonomi penambang pasca penambangan emas. Penelitian ini mengunakan penelitian kualitatif dengan tipe deskriptif. Pemilihan informal dalam penelitian ini mengunakan tehnik purposive sampling. Jenis data adalah data primer dan data skunder. Metode pengumpulan data dilakukan dalam dua cara: observasi, wawancara. Hasil penelitian pasca penambangan emas tidak ada penanggulangannya, sawah yang telah habis digarap dibiarakan begitu saja menjadi rawa dan pasir. Status sosial pascapenambangan jadi ibu rumah tangga tukang ojek, buruh tani dan buruh penambang emas. Juga terjadi penurunan pendapatan.
\end{abstract}

Kata Kunci :Sosial Ekonomi, Penambang, Perubahan Mata Pencarian 


\section{PENDAHULUAN}

Indonesia merupakan salah satu negara yang mempunyai potensi tambang emas terbesar di dunia. Potensi tersebut terbesar dari seluruh provinsi Aceh sampai Papua. Sejak zaman pemerintah kolonial Belanda, telah dilaksanakan aktifitas eksploitasi kekayaan tambang emas. Sebut saja di Rejang Lebong, Bengkulu, Cikotok, dan daerah lainya. Potensi edapan terdapat di hapir seluruh daerah Indonesia, seperti pulau Sumatera, Kepulauan Riau, Kepulauan Jawa, Pulau Sulawesi, Nusa Tengara, Maluku, dan Papua (Diantoro, 2010).

Peres mancatat bahwa emas terdapat hampir semua pelabuhan di Sumatera (Guillot, 2007). Sumatera Barat merupakan salah satu provinsi yang juga memiliki cadang tambang emas sehinga sebagian masyarakat bermata pencarian sebagai penambang emas. Menurut laporan Dinas pertambangan emas dan energi propinsi Sumatera Barat tahun 2004, wilayah Sumatera Barat yang terdapat kandungan emas terdapat pada daerah Kabupaten Sijunjung, Lima Puluh Kota, Pasaman, Solok Selatan, dan Pesisir Selatan. Untuk Kabupaten Sijunjung, deposit emas diperkirakan terdapat sejumlah lokasi yang melakukan kegiatan pertambangan, seperti: Bukit Kabu, Tanjung Ampalu, dan Jorong Koto Panjang.

Berdasarkan penelitian di Jorong Koto Panjang, masyarakat sekitar banyak yang terlibat dalam kegiatan pertambangan emas. Dalam hal ini pertambangan emas adalah suatu perkerjaan dan pendapatan utama penambang dan kelurga. Penambang emas di Jorong Koto Panjang di lakukan secara ilegal, karena tidak memiliki izin.

Penambang emas tidak lagi dilakukan dengan cara mendulang pasir yang ada di pinggiran sungai, tetapi sejumlah penduduk di jorong koto panjang sudah melakukan pengalian pasir pada aliran sungai dan dilakukan penyaringan secara mekanis dengan mengunakan tenaga mesin pompa, dan dengan cara box yaitu mengunakan alat berat (tractor) sehinga sejumlah emas yang didapatkan juga lebih banyak, ekspolorasi emas bukan hanya dilakukan di aliran sungai namum merabat kesawah-sawah milik masyarakat. Aktifitas penambangan tidak lagi dijadikan sebagai pekerjaan sampingan, namun telah menjadi usaha dengan membutuhkan modal yang relatif besar.

Penduduk Jorong Koto Panjang di tinjau dari segi mata pencarian, pada umunya bermata pencarian sebagai penambang emas. Kehadiran tambang emas di Jorong Koto Panjang mempengaruhi mata pencarian masyarakat, dari petani menjadi penambang emas, penambang emas dilakukan di area persawahan, sehinga banyak lahan pertanian sawah yang berubah fungsi menjadi area tambang emas. Peralihan mata pencarian dari petani penambang emaspun terhaji, hal ini dikarenakan penambang emas lebih menguntungkan, uang yang diperoleh relatif lebih banyak, sehinga kebutuhan masyarakat tercukupi dibandingkan bertani yang hanya panen tiga kali setahun dan hasilnya pas-pasan. Pada tahun 2012 jumlah kepala keluaga di Jorong Koto Panjang yang bermata pencarian sebagai penambang emas ada 420 kepala keluarga, sedangkan sawah yang rusak akibat penambang emas dimiliki oleh 173 kepala keluarga.

Aktifitas tambang mulai sejak tahun 2005 yang kemudian mempengaruhi dimamika dan aspek kehidupan masyarakat di Jorong Koto Panjang. Area pertanian, yang dahulunya sawah, saat ini dipenuhi oleh mesin-mesin yang dipergunakan untuk aktifitas tambang, seperti mesin dompeng dan box. Kondisi ini menyebabkan terjadi peningkatan perkenomian masayarakat yang berdampak pada berubahnya gaya hidup yang dulu relatif miskin dan menjadi kaya sehinga menimbul pola hidup konsumtif. Namun peningkatan ekonomi masyarakat dapat dilihat dari kemampuan masyarakat dalam membeli motor, mobil, perabotan rumah tangga, merenovasi rumah, serta memiliki kemampuan melanjutkan pendidikan anak-anak mereka ke Perguruan Tinggi.

Realitras ini mempengaruhi stratifikasi sosial dalam masyarakat. Dahulunya stratifikasi sosial masyarakat berdasarkan luas kepemilikan lahan, namun mulai berubah, seperti pada tahun 2005 dengan kehadiran tambang emas di Jorong Koto Panjang orang yang menepati strata atas adalah orang yang memiliki penghasilan besar dari hasil tambang emas. Sedangkan bagi pekerja di lahan tambang menempati lapisan bawah. Hal ini berubah 
pasca penambangan emas, dimana yang menempati strata atas adalah orang-orang yang memeliki pekerjaan tetap seperti, wiraswata, PNS, pegawai swasta dan insvestor bekerja sebagai penambang emas.

Pada tahun 2012 sampai sekarang penambang emas tersebut mengalami kondisi sulit karena sudah habisnya cadangan emas yang terdapat pada lahan milik petani. Area sawah yang dijadikan area tambang tersebut dibiarkan, karena kandungan emas telah habis, serta kondisinya telah rusak. Perubahan yang terjadi pasca penambang emas, masyarakat sekitar kehilangan sawah, mereka tidak dapat mengarap sawah lagi karena telah rusak oleh penambang emas kondisi sawah tersebut menjadi rawa-rawa dan pasir. Disamping itu pemilih sawah tidak bekerja sebagai penambang lagi, mereka mencari pekerjaan baru untuk menghidupi keluarga mereka. Masyarakat menyesal telah menjadikan sawah mereka sebagai area penambangan emas.

Berdasarkan realitas yang terjadi dimasyarakat tulisan ini mengkaji status sosial ekonomi keluarga pemilik sawah pascapenambangan emas di Jorong Koto Panjang Nagari Limo Koto Kecamatan Koto VII Kabupaten Sijunjung.

\section{TINJAUAN PUSTAKA}

Persoalan kerusakan lingkungan rusak akibat aktifitas masyarakat manusia telah banyak ditulis. Seperti dalam tulisan yang berjudul Puar Cama untuk Anak Cucu; Kearifan Lokal untuk Sustainability Forest di Manggarai Barat yang ditulis Firdaus. Dalam tulisan dibahas fungsi hutan bagi masyarakat manggarai untuk menyangga daratan dan pemasok air bersih, namun aktifitas eksploitasi tangan-tangan didak bertanggung jawab, berimplikasi terhadap ekosistem hutan dan berkurangnya flora fauna hutan. Padahal sebelum aktifitas eksploitasi, masyarakat adat Manggarai telah memiliki mekanisme adat dalam menjaga hutan yag disebut puar cama (Firdaus, 2012). Tulisan terebut menawarkan mekanisme pengelolan hutan bersama dengan mengadopsi prinsip puar cama, agar kebutuhan masyarakat Manggarai terpenuhi dan terdapat pengontrolan pemanfaatan hutan secara adat.
Penelitian tentang aktifitas eksloitasi terdahap lingkungan alam, seperti aktifitas penambangan pernah dilakukan sebelumnya. Seperti penelitian tentang kondisi sosial ekonomi penambang emas pernah ditulis sebelumnya oleh Sari, dalam tulisan yang berjudul: Kehidupan Sosial Ekonomi Penambang Emas Rakyat di Nagari Tambang. Kecamatan IV Jurai Kabupaten Pesisir Selatan tahun 1985-2010. Berdasalkan hasil penelitian penambang emas di Nagari tambang beroperasi sejak tahun 1913 dimana awal pengoperasian tambang emas ini di kelola oleh pemerintahan india belanda, baru tahun 1985 tambang emas ini di kelola oleh warga setempat dan sampai sekarang penambang emas masih berlansung. Kajian ini membahas sejarah penambangan emas rakyat, serta mengulas stratifikasi sosial penambang pada zaman pemerintah Hindia Belanda. Masyarakat berada diposisi buruh kasar dengan upah minimum sampai tahun 1985, dan penambang merupakan masyarakat setempat. Penambangan emas ini mencapai puncak kejayaan pada tahun 1985-1990 sehinga merubah kehidupan ekonomi masyarakat yang lebih baik dari sebelumnya sampai tahun 2010. Pengahsilan masyarakat dari melakukan penambangan mengalami kemerosotan sehinga akhirnya banyak masyarakat yang tidak melakukan penambangan lagi. Penyebabnya kekurangan modal, managemen penambangan kurang efisien, serta aturan dalam penambangan, karena menyebabkan kerusakan lingkungan (Sari, 2011).

Selain itu juga pernah dilakukan penelitian oleh Nike, dengan judul penelitian: Pengaruh Aktivitas Tambang Emas bagi Kesejahteraan Masyarakat di Sumbarang Ombak Kenangarian Muaro Kecamatan Sijunjung Kabupaten Sijunjung. Penelitian terdapat pengaruh signifikan dari tingkat pendidikan terhadap kesejahteraan masyarakat penambang emas di Jorong Sumbarang Ombak Kenagarian Muaro Sijunjung Kabupaten Sijunjung yaitu: hubungan pendidikan tehadap tingkat kesejahteraan penambang cukup tinggi. Terdapat pengaruh signifikan dari tingkat pekerjaan terhadap kesejahteraan masyarakat penambang emas di jorong sumbarang ombak kenagarian muaro 
sijunjung kabupaten sijunjung yaitu: hubungan pekerjaan terhadap kesejahteraan masyarakat. Terdapat pengaruh signifikan dari tingkat lapangan pekerjaan terhadap kesejahteraan masyarakat penambang emas di Jorong Sumbarang Ombak Kenagarian Muaro Sijunjung Kabupaten Sijunjung yaitu: hubungan lapangan pekerjaan terhadap tingkat kesejahteraan masyarakat cukup tinggi. Serta terdapat pengaruh signifikan dari tingkat pendapatan terhadap kesejahteraan masyarakat penambang emas di Jorong Sumbarang Ombak Kenagarian Muaro Sijunjung Kabupaten Sijunjung yaitu: hubungan pendapat dengan tingkat kesejahteraan masyarakat penambang cukup tinggi (Nike, 2011).

Berbeda dengan tulisan diatas, meskipun sama-sama membahas aktifitas penambangan emas dan kondisi sosialekonomi penambang, namun tulisan ini membahas kondisi sosial ekonomi para petani yang menjadi penambang, pascaaktifitas penambangan, yang membuat mereka mencari pekerjaan lain dan perubahan pendapatan.

\section{METODE PENELITIAN}

Pendekatan dalam penelitian ini mengunakan pendekatan kulitatif karena pendekatan ini mengungkapkan realita sebagaiman adanya. Menurut bogdan dan taylor dalam Moleong, prosedur yang menghasilkan deskripsi berupa kata kata tertulis atau lisan dan penelitian ini untuk memahami fenomena tentang apa yang di alami oleh subjek penelitian misalnya prilaku, presepsi, motivasi, tindakan dll (Moleong, 2007:4-6). Kemudian yang dikumpulkan adalah berupa kata-kata gambaran dan bukan angka-angka.

Informan dalam penulisan ini adalah para petani yang bealih menjadi penambang. Disamping itu yang menjadi informal dalam penelitian ini adalah tokoh adat dan tokoh masyarakat. Pengumpulan data dilakukan dengan cara observasi dilakukan untuk mengamati tingkah laku yang aktual mengenai hal-hal yang yang berkaitan dengan masalah dalam penelitian. Seperti mengamati aktifitas petani yang pernah menjadi penambang. Wawancara dilakukan adalah wawancara mendalam.

\section{PIHAK TERLIBAT DALAM PENAMBANGAN}

Adapun pihak yang terlibat penambangan emas tersebut di antaranya investor, pemilih lahan, operator mandor dan pekerja kasar, luas lahan yang akan di garap menjadi tambangan emas minimal 1 $\mathrm{Ha}$, dengan jumlah pekerja minimal pekerja 6 orang.

Investor adalah orang yang membiayai modal untuk kebutuhan tambang emas seperti traktor, karpet, mesin, dan lain-lain. Di antaranya banyak investor yang bekerja di penambangan emas di Jorong Koto Panjang. Investor di sini menepati strata atas dalam masyarakat karena mereka mempunyai uang dan mampu beri modal dalam aktivitas tambang. Operator adalah orang yang bekerja membawa alat berat seperti tractor sistem kerjanya perjam dan biasa di gaji Rp.50.000 per jam per orang. Operator memiliki keahlian membawa alat tractor.

Selain itu juga ada mandor yang bekerja sebagi pengawas lapangan tambangang emas. Dan oarang yang menjadi mandor biasanya orang kepercayaan orang yang mengola atau oarang yang memiliki lahan tamabang emas, menjadi mandor harus dapat di percaya dan banyak mencari peluang agar orang dapat disenang dan percaya dengan kita sehinga kita dapat bekerja sama dengan orang tersebut. Dan mereka melakukan pekerjaan dari satu lokasi ke lokasi. Golongan paling bawah adalah Pekerja kasar, yaitu orang yang bekerja sebagai anak buah di tambang. Seperti membuang batu, membuka talang emas dan lain-lain. Pekerja kasar ini berda pada stara bawah dalam tambang emas. Pekerja kasar hanya mengandalkan otot.

Bukan hanya keluarga pemilik sawah pascapenambangan saja mengeluh setelah sawah habis di garap bahkan insvestor, operator, mandor, dan pekerja kasar juga mengeluhkan untuk mengidupikelurga mereka karena mata pencarian untuk mengantung pada penambang emas pada saat ini mereka masih mengandalakan tambang emas sebagai mata pencarian mereka untuk menghidupi keluarga.

Hal ini sesuai dengan teori struktural fungsional tidak akan berjalan satu lembaga kalau tidak saling bekerja sama. Begitu pula dengan tambang emas yang ada di Jorong 
Koto Panjang antara pemilik lahan, investor, mandor, opereator, dan pekerja kasar tambang emas mereka membentuk suatu struktur yang saling membutuhkan atau berkaitan satu sama lain, jika salah satu tidak ada dalam suatu tambang emas tersebut maka tidak akan berjalan dan mendapatkan hasil.

\section{KONDISI AREA PERTANIAN PASCA AKTIFITAS PENAMBANGAN}

Area sawah milik petani telah dijadikan area tambang emas. Dari keseluruhan sawah yang menjadi area tambang, pasca aktifitas penambangan emas, sawahnya telah rusak. Dari sepuluh petani yang memiliki sawah dijadikan area pertambangan, menyatakan lahan mereka menjadi rusak. Awalnya petani tertarik melakukan penambangan di sawah milik mereka, karena meyakini terdapat kandungan emas. Adanya tambang emas di Jorong Koto Panjang ini menyebabkan pelarihan mata pencarian masyarakat dari petani beralih pada penambang emas.

Saat menjadikan lahan sebagai are tambang, masyarakat belum menyadari dampak yang ditanggung kedepannya. Namun kenyataan yang terjadi sekarang pascapenambangan banyak sawah yang rusak terbengkalai menjadi rawa dan pasir.

\section{ALIH FUNGSI LAHAN PERTANIAN MENJADI AREA TAMBANG}

Alasan petani menjadikan sawah mereka menjadi tambang emas, berdasarkan data dari informan adalah tuntutan ekonomi, dan kehadiran tambang emas ini juga merubah mata pencarian dari petani sawah kepada penambang emas. Penambang emas adalah salah satu pekerjaan masyarakat untuk mendongkarak dan memenuhi kebutuhan ekonomi masyarakat di Jorong Koto Panjang. Dengan adanya tambang emas tersebut kehidupan masyarakat dapat tercukupi atau terpenuhi serta meningkatnya kesejahteraan kelurga yang terbukti dengan sudah banyaknya masyarakat yang memiliki rumah permanen, kendaraan, serta tidak langsung penambangan emas ini berimplikasi terhadap terbukanya lapangan pekerjaan bagi masyarakat. Namun pascapenambangan emas ini, ekonomi kelurga pemilik sawah menurun karena pada umumnya lahan di tinggalkan begitu saja menjadi rawa dan pasir-pasir sehinga tidsak dapat digunakan lagi untuk area pertanian.

Alih fungsi lahan dirasakan sangat menjanjikan untuk mendongkrak perekonomian masyarakat yang semulanya menggantungkan kepenuhan kebutuhan hidup sebagai petani. Pertanian dianggap membuat kondisi perekonomian relatif sulit berubah. Ditambah membutuhkan kesabaran untuk mendapatkan hasil pertanian yang baik. Dengan menjadikan area tambang masyarakat meyakini terjadi perubahan dalam hidup, hal ini mendorong mereka mengalihkan fungsi sawah mereka menjadi tambang emas demi uang dan kelangsungan hidup mereka.

Alih fungsi ini menimbulkan dampak negatif dari penambangan emas di antaranya terjadi kerusakan dan pencemaran lingkungan seperti sawah menjadi rusak rawa-rawa pasir dan air singai menjadi kotor akibat dari penambangan emas tersebut berdesarkan analisis dari informan diketahui bahwa mereka menjadikan sawahnya menjadi tambang emas karna mempunyai alasanalasan yang berbeda, mereka memikirkan kerusakan yang akan terjadi namun demi kebutuhan mereka mengorbankan sawah mereka, dan sawah tersebut tidak bisa di gunakan lagi sebagai area pertanian untuk sawah, kenyataannya mereka memikirkan dampak dari kerusakan yang akan terjadi akibat penambang emas tersebut.

Kondisi kerusakan terhadap lahan dirasakan oleh masyarakat. Penyesalan adalah suatu perasaan dimana seorang merasa bersalah karna telah melakukan kesalahan yang pernah ia perbuat dalam hidupnya dan penyesalan selalu datang belakangan. Pemilik sawah yang mengetahui dan menyesali akibat dari penambangan emas tersebut, sawah mereka rusak dan ditinggalkan terbekalai sehinga tidak dapat di manfaatkan lagi untuk usaha pertanian.

Penyesalan disampaikan masyarakat seperti sewaktu mereka mempunyai uang yang banyak yang diperoleh dari penambangan, uang mereka gunakan untuk kebutuhan kelurga tanpa memikirkan invertasi, seperti kelanjutan dari pendidikan. 


\section{PERUBAHAN SOSIAL EKONOMI PASCA PENAMBANGAN}

Terjadi perubahan pendapatan, sewaktu menambang emas, menjadikan sawah sebagai area penambangan. Terjadi peningkatan.Pendapatan saat terjadi penambangan dengan rentang Rp 3.000.000 sampai $\mathrm{Rp} 5.000 .000$ perminggu. Untuk lebih jelasnya dapat dilihat dari tabel berikut:

Tabel 1

Pendapatan Per Minggu Saat Menambang

\begin{tabular}{|l|l|c|c|}
\hline No & Nama & >1 Juta & > 3 Juta \\
\hline 1. & Virdana & - & $\checkmark$ \\
\hline 2 & Wirdati & - & $\checkmark$ \\
\hline 3 & Julisman & $\checkmark$ & - \\
\hline 4 & Ramli & - & $\checkmark$ \\
\hline 5 & Supardi & - & - \\
\hline 6 & Jasmar & $\checkmark$ & $\checkmark$ \\
\hline 7 & Gulmi & - & $\checkmark$ \\
\hline 8 & Ermayunita & - & $\checkmark$ \\
\hline 9 & Ermawilis & - & $\checkmark$ \\
\hline 10 & mardi & - & $\checkmark$ \\
\hline & Jumlah & $\mathbf{2}$ & $\mathbf{8}$ \\
\hline
\end{tabular}

Sumber : Data Primer 2013

Kondisi berbeda saat pasca penambangan, pendapatan menurun berkiran Rp 300.000 sampai Rp 500.000 perminggu. Untuk lebih jelasnya dapat dilihat berdasarkan tabel berikut

\section{Tabel 2}

Pendapatan Pasca Penambangan Per Minggu

\begin{tabular}{|c|c|c|c|c|}
\hline \multirow{2}{*}{ No } & \multirow{2}{*}{ Nama } & \multicolumn{3}{|c|}{$\begin{array}{c}\text { Pendapatan (Dalam } \\
\text { Ribuan) }\end{array}$} \\
\hline & & $\begin{array}{l}\text { Rp.300 } \\
-400 .\end{array}$ & $\begin{array}{c}\text { Rp.4.00 } \\
-5.00\end{array}$ & $>$ Rp.500 \\
\hline 1. & Virdana & - & $\checkmark$ & - \\
\hline 2 & Wirdati & $\checkmark$ & - & - \\
\hline 3 & Julisman & - & - & $\checkmark$ \\
\hline 4 & Ramli & - & $\checkmark$ & - \\
\hline 5 & Supardi & - & $\checkmark$ & - \\
\hline 6 & Jasmar & - & $\checkmark$ & - \\
\hline 7 & Gulmi & - & - & $\checkmark$ \\
\hline 8 & Ermayunita & - & $\checkmark$ & - \\
\hline 9 & Ermawilis & - & $\checkmark$ & - \\
\hline 10 & Mardi & - & - & $\checkmark$ \\
\hline & Jumlah & 1 & 6 & 3 \\
\hline
\end{tabular}

Sumber : Data Primer 2013

Berkurangnya pendapatan ini membuat penambang banyak mengeluh karena susahnya mencari pekerjaan dan mendapatkan untuk kebutuhan hidup mereka. Sawah yang mereka gunakan untuk betani sekarang sudah rusak akibat dari pertambangan emas.Pendapatan informan penambang emas mengalami penurunan ini terlihat dari jumlah pendapatan informan skarang pascapenambang emas yang dijelaskan sebelumnya terjadi penurunan

akan tetapi untuk biaya pendidikan mereka tetap mengutamakan pedidikan anak mereka. Berdasarkan analisi dari wawancara beberapa infoman pasca penambang emas tidak menggu pendidikan anak, apapun yang terjadi informan tetap mementingkan pendidikan anaknya selagi anak tersebut mau untuk sekolah. Pemenuhan kebutuhan pendidikan anak yang dilakukan seperti tertera dalam tabel berikut:

Tabel 3

Perbandingan Fasilitas Penunjang

Pendidikan Anak, Sebelum \& Pasca Penambangan

\begin{tabular}{|c|c|c|}
\hline No & Dulu & Sekarang \\
\hline 1 & Pakai motor & Masih pakai motor \\
\hline 2 & $\begin{array}{l}\text { Uang belanja } \\
\text { banyak (Rp. } \\
40.000 \text { perhari) }\end{array}$ & $\begin{array}{lr}\text { Uang } & \text { belanja } \\
\text { kurang } & \text { (Rp.10.000 } \\
\text { perhari } & \end{array}$ \\
\hline 3 & $\begin{array}{ll}\text { Baju } & \text { seragam } \\
\text { ada } & \end{array}$ & Baju seragam ada \\
\hline 4 & $\begin{array}{l}\text { Buku-buku } \\
\text { sekolah ada }\end{array}$ & $\begin{array}{l}\text { Buku-buku sekolah } \\
\text { ada }\end{array}$ \\
\hline 5 & $\begin{array}{l}\text { Kebutuhan } \\
\text { sekolah ad }\end{array}$ & $\begin{array}{l}\text { Kebutuhan sekolah } \\
\text { ada }\end{array}$ \\
\hline
\end{tabular}

Sumber : Data Primer 2013

Berdasarkan data pada tabel yang di paparkan maka dapat disimpulkan bahwa pendapatan informan baik adanya tambang emas ataupun tidak adanya tambang emas tidak menggangu pendidikan anak mereka hanya saja uang saku anak mereka yang dikurangi.

Hasil penelitian juga menunjutkan bahwa pendapatan akan kebutuhan hidup tidak bisa dikatakan cukup. Selagi ada uang akan di manfaatkan untuk kebutuahan hidup lainya karena manusian mempunyai sifat tidak pernah puas akan kehidupannya dan di dalam kelurga tidak jarang adanya pola hidup konsumtif. Konsumtif yaitu membeli yang seharusnyabukan membeli hal-hal yag diperlu saja. Dan dari hasil 
analisis wawancara dari beberapan informan di peroleh informasi bahwa keluarga pemilik sawah adanya pola hidup konsumtif hal ini terlihat dengan adanya barang-barang yang ada di dalam rumah merekadan peralatan rumah tangga yang dimilki sewaktu menambang. Berikut tabel barang-brang rumah tangga yang dimiliki informan:

Tabel 4

Data Perabotan dan Alat Elektronik Milik Penambang

\begin{tabular}{|c|l|c|}
\hline No & \multicolumn{1}{|c|}{ Dulu } & Keterangan \\
\hline 1 & Tv & Masih yang lama \\
\hline 2 & Kursi & Masih yang lama \\
\hline 3 & Rumah & Masih yang lama \\
\hline 4 & Kendaraan & Masih yang lama \\
\hline 5 & Lemari & Masih yang lama \\
\hline 6 & $\begin{array}{l}\text { Alatl-alta rumah } \\
\text { tangga }\end{array}$ & Masih yang lama \\
\hline
\end{tabular}

Maka berdasarkan tabel di atas dan pejelasan dari informan sebelumnya dapat disimpulkan bahwa mereka membeli barang kebutuhan rumah tangga ketika mempunyai uang dan telah menjadi kehidupan konsumtif dalam keluarga informan.

Berdasarkan pembahasan sebelumnya pendapatan informan penambangan emas mengalami penurunan tetapi tidak menggangu pendidikan anak mereka namun sewaktu informan menambang dan mempunyai uang terlihat adanya pola kehupan konsumtif dalam keluarga mereka.

\section{KESIMPULAN}

Keberadaan penambangan emas di Jorong Koto Panjang, telah membawa perubahan terhadap masyarakat masyarakat jorong koto panjang, di mana dahulunya masyarakat koto panjang bermata pencarian sebagai petani kini sebagai penambang emas, hal ini terlihat bahwa $70 \%$ masyarakat Jorong Koto Panjang sudah mengalami peningkatan yang terlihat sudah banyaknya rumah penduduk permanen dan sudah banyaknya rumah penduduk yang permanen dan sudah adanya tiap rumah memiliki kendaraan.
Kondisi sawah yang telah selesai di tambang di biarkan begitu saja

Pendapatan kelurga pemilik sawah pascapenambangan masyarakat di Jorong Koto Panjang Nagari Limo Koto Kecamatan Koto VII Kabupaten Sijunjung mulai menurun dari biasanya yaitu berkisar \pm 500 ribu perkeluarga, dan menjadi pekerja kasar, tukang ojek mengumpulkan getah untuk memenuhi kebutuhan hidup mereka sehari-hari.

Orang yang terlibat penambang emas bukan hanya pemilik sawah di antara investor, operator, mandor dan pekerjaan kasr penambang emas dan dari masing masing pekerjaan tersebut dapat menentuka starifiksi diantara masyarakat yang mana apapun pekerjaannya jika mereka memilki kejayaan dan uang maka mereka berada di stara atas, dan begitu sebaliknya, sewaktu menambang emas mereka menepatai stara atas namu pascapenambang emas selesai mereka kembali ke strata sebelumnya. Dan dari adanya pascapenambang emas tersebut merubah mata pencarian dan pola hidu juga status sosial yang di milki dalam masyarakat.

\section{DAFTAR PUSTAKA}

Diantoro, V. (2010). Emas Investasi dan Pengolahannya. Jakarta: PT Gramedia.

Firdaus, F. (2012). Puar Cama Untuk Anak Cucu: Kearifan Lokal Untuk Sustainability Forest di Manggarai Barat. Jurnal Ilmu Sosial Mamangan, 1(1), 39-50.

Guillot, C. (2007). Barus Seribu Tahun yang Lalu. Bogor: Grafindo Mardi Rosdakarya.

Nike, M. Y. (2011). Pegaruh Aktivitas Tambang Emas Bagi Kesejahteraan Masyarakat di Jorong Subarang Ombak Kenagarian Muaro Kecamatan Sijunjung Kabupaten Sijunjung. STKIP PGRI Sumatera Barat.

Sari, P. R. (2011). Tambang Emas Rakyat di Nagari Koto Baru Kecamatan IV Nagari Kabupaten Sijunjung Tahun 2003-2010. STKIP PGRI Sumatera Barat. 


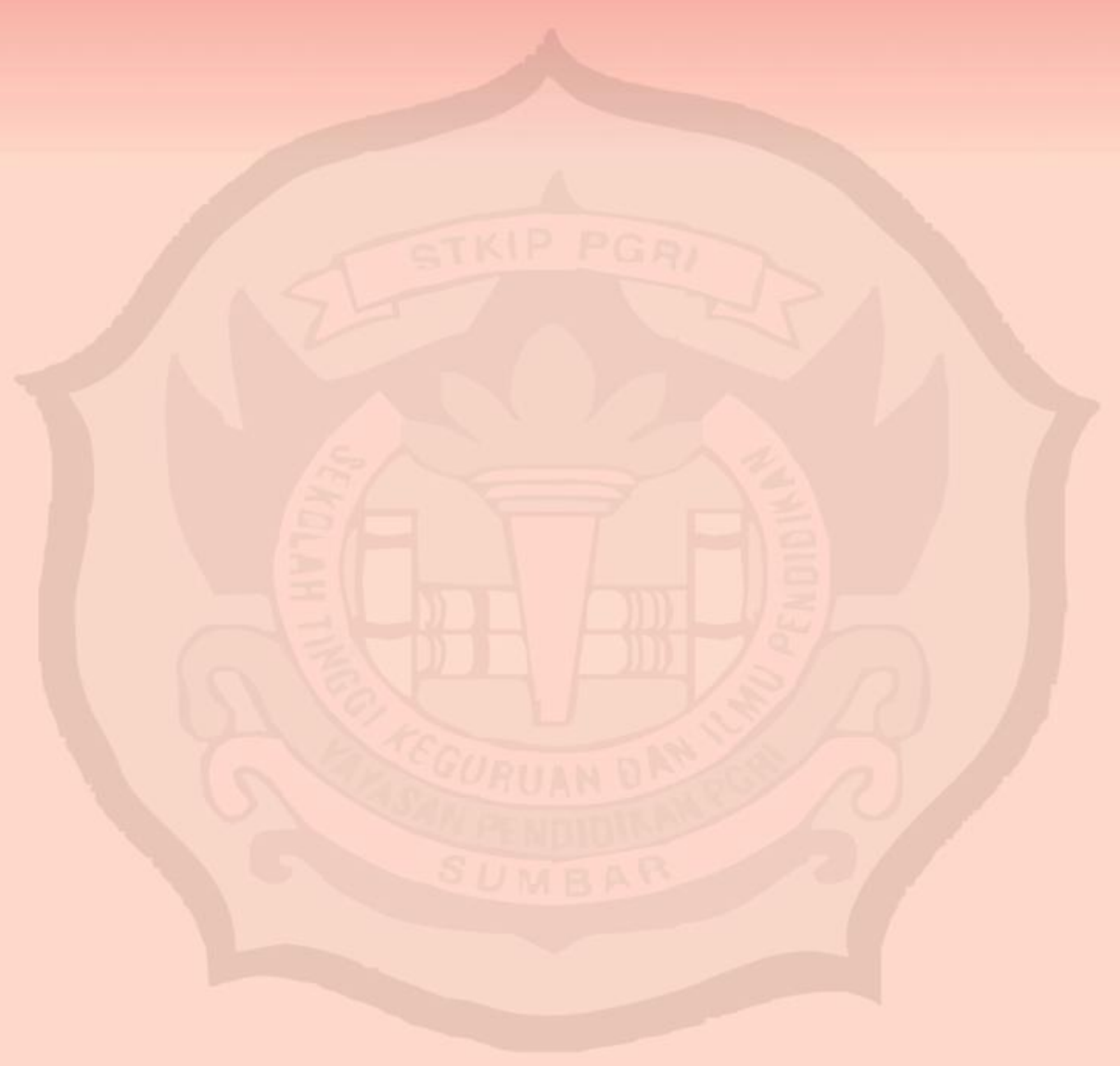

Penerbit :

Laboratorium Program Studi Pendidikan Sosiologi, STKIP PGRI Sumatera Barat

Kampus STKIP PGRI, Jl. Gunung Pangilun, Padang, Sumatera Barat

Email : redaksimamangan@gmail.com 